\title{
The Topographic Peculiarities of the Formation of Nanosized Particles from Metallopolymers
}

\author{
A.D. Pomogailo*, G.I. Dzhardimalieva \\ AND A.S. ROSENBERG \\ Institute of Problems of Chemical Physics, Russian Academy of Sciences \\ 142432, Chernogolovka, Moscow Region, Russia \\ The morphology of solid phase products of thermal transformation of \\ transition metal acrylates or its cocrystallites is studied. The thermal trans- \\ formation of the metal-containing monomers studied consists in dehydration, \\ solid phase polymerization and thermolysis process. The topography of the \\ initial compounds and solid phase products of thermal decay, as well as their \\ composition, are analyzed by optical and electron microscopies. The aver- \\ age particle sizes, $d_{\mathrm{EM}}$, are: $6.0-13.0 \mathrm{~nm}$ in the case of $\mathrm{FeAcr}_{6}$ (based on the \\ data of electron diffraction, the main product is $\left.\mathrm{Fe}_{3} \mathrm{O}_{4}\right), 6.0 \mathrm{~nm}$ for $\mathrm{FeCoAcr}_{8}$ \\ and $\mathrm{Fe}_{2} \mathrm{CoAcr}_{14}\left(\mathrm{Fe}_{3} \mathrm{O}_{4}, \mathrm{CoO}, \mathrm{Fe}_{2} \mathrm{CoO}_{4}\right)$, and $6 \mathrm{~nm}$ for $\mathrm{CoMal}_{2}(\mathrm{CoO})$. The \\ material formed consists of nanosized metal particles uniformly allotted in \\ polymer matrix.
}

PACS numbers: 81.07.- b, 81.07.Bc

\section{Introduction}

In chemical reactions of the solid phase the morphological characteristics of the starting compounds, such as dispersity, specific surface, and topography of the particles, are the most important factors which influence the velocity of the process. On the one hand, the knowledge about the evolution of the morphology of solid phase products allows one to estimate the kinetic peculiarities of the process. On the other hand, the study of the topography of solid phase products, in particular, at the end of the transformation, permits us to understand physicochemical properties of the materials formed [1]. In this respect the morphology of metal-containing polymer nanocomposites obtained, for example, by thermolysis of corresponding metal-containing monomers in the regime of self-organization, has been little studied.

* corresponding author; e-mail: adpomog@icp.ac.ru 
In the last years we have elaborated the approach including synthesis of metal-containing polymers during the thermal transformation of the metal-containing monomers, combined with generation and growth of the particles of the metal or metal oxides and their simultaneous stabilization by polymers. This paper deals with the study of the morphology during the thermal transformation of the unsaturated metal carboxylates - transition metal acrylates $\left(\mathrm{MAcr}_{2}\right)$ and maleates $\left(\mathrm{MMal}_{n}\right)$, where $\mathrm{M}$ is $n$-valence metal, Acr is the acrylic group $\left(\mathrm{CH}_{2}=\mathrm{CHCOO}\right)$, $\mathrm{Mal}$ is the maleic group ( $\mathrm{OOCCH}=\mathrm{CHCOO}$ or $\mathrm{OCOCH}=\mathrm{CHCOOH})$. These are: $\mathrm{Cu}_{2}\left[\mathrm{CH}_{2}=\mathrm{CHCOO}\right]_{4} \cdot 2 \mathrm{C}_{2} \mathrm{H}_{5} \mathrm{OH}\left(\mathrm{CuAcr}_{2}\right)[2]$,

$\mathrm{Co}\left[\mathrm{CH}_{2}=\mathrm{CHCOO}\right]_{2} \cdot \mathrm{H}_{2} \mathrm{O}\left(\mathrm{CoAcr}_{2}\right)[3]$,

$\mathrm{Ni}\left[\mathrm{CH}_{2}=\mathrm{CHCOO}\right]_{2} \cdot \mathrm{H}_{2} \mathrm{O}\left(\mathrm{NiAcr}_{2}\right)[4]$,

$\mathrm{Co}[\mathrm{OOCCH}=\mathrm{CHCOO}] \cdot 2 \mathrm{H}_{2} \mathrm{O}\left(\mathrm{CoMa}_{2}\right)[5]$,

iron $\mu_{3}$-oxoacrylate $\mathrm{Fe}_{3} \mathrm{O}(\mathrm{OH})\left[\mathrm{CH}_{2}=\mathrm{CHCOO}\right]_{6} \cdot 3 \mathrm{H}_{2} \mathrm{O}\left(\mathrm{FeAcr}_{6}\right)[6]$

and $\mu_{3}$-oxomaleate $\mathrm{Fe}_{3} \mathrm{O}(\mathrm{OH})[\mathrm{OOCCH}=\mathrm{CHCOOH}]_{6} \cdot 3 \mathrm{H}_{2} \mathrm{O}\left(\mathrm{FMal}_{6}\right)[7]$,

cocrystallites $\mathrm{FeAcr}_{6}-\mathrm{CoAcr}_{2}$ and $\mathrm{FeAcr}_{6}-\mathrm{NiAcr}_{2}$ with atomic ratio

$\mathrm{Fe}: \mathrm{Co}=1: 0.8\left(\mathrm{FeCoAcr}_{8}\right)$ and $\mathrm{Fe}: \mathrm{Co}=2: 1\left(\mathrm{Fe}_{2} \mathrm{CoAcr}_{14}\right)[8]$,

$\mathrm{Fe}: \mathrm{Ni}=2: 1\left(\mathrm{Fe}_{2} \mathrm{NiAcr}_{14}\right)[4]$,

as well as polymeric $\mathrm{Ni}$ acrylate of different metal content, obtained by polymerization of the $\mathrm{NiAcr}_{2},\left[\mathrm{Ni}\left(\mathrm{CH}_{2} \mathrm{CHCOO}\right)_{2}\right]_{n}(\mathrm{NiPacr}-1)$, and by the polymer-analogous reaction of polyacrylic acid with $\mathrm{Ni}(\mathrm{II})$ acetate, $\left[\mathrm{Ni}_{m}\left(\mathrm{CH}_{2} \mathrm{CHCOO}\right)_{n}\right](\mathrm{NiPAcr}-2)$. The thermolysis of the compounds studied [2-8] is accompanied by gas evolution and the mass loss, that is caused by three consequent temperature-distinguished macrokinetic processes: dehydration (in the case of crystal hydrates) - 373-393 K; radical solid phase (co)polymerization - 453-493 $\mathrm{K}$; and decarboxylation of (co)polymers formed $>573 \mathrm{~K}\left(>493 \mathrm{~K}\right.$ in the case of $\left.\mathrm{CuAcr}_{2}\right)$.

\section{Experimental}

The metal carboxylates are obtained as described previously [8]. Thermolysis of the compounds is carried out under isothermal conditions. The kinetics of conversion was monitored taking into account gas evolution in self-generated atmosphere (the sample is previously vacuated at $293 \mathrm{~K}$ and pressure $1 \mathrm{~Pa}$ for $0.5 \mathrm{~h}$ ) in static nonisothermal reactor, using the membrane null-manometer (the heating volume of the reactor vessel did not exceed $0.05 \mathrm{~V}$, where $V$ was the volume of the reactor vessel). After completion of the thermolysis, the amount of gases evolved and the weight loss of the samples $(\Delta m, \mathrm{~g})$ were determined, and low-temperature fractionation $(77 \mathrm{~K}$ ) of the gaseous products was carried out. Optical microscopic (OM) studies were carried out on an MBI-6 instrument using transmitted polarized and nonpolarized light. Electron microscopy studies were performed using the HU-125 transmission electron microscope with accelerating voltage of $100 \mathrm{kV}$. The specific surfaces $\left(S_{\mathrm{sp}}^{0}, \mathrm{~m}^{2} / \mathrm{g}\right)$ of the powders were determined from the low-temperature adsorption of nitrogen. 


\section{Results and discussion}

\subsection{The morphology of the initial metal-containing monomers}

All compounds studied are the powders with rather extended $S_{\mathrm{sp}}^{0}$. The main characteristics of the dispersity of the compounds are given in Table.

$\mathbf{C u A c r} 2$. According to the data of optical microscopy, the initial samples of $\mathrm{CuAcr}_{2}$ are composed of bright green crystals, mainly in the form of plates, and of their splices with the somewhat spongy surface (which is due to alcohol desolvation). Needle-shaped prismatic crystals and amorphous glassy products are also formed in a small proportion (up to 10 mass $\%$ ). The average size of the plates amounts to $(5 \div 20) \times(5 \div 50) \times(1 \div 5) \mu \mathrm{m}^{3}$ although particles with dimensions below $2 \mu \mathrm{m}^{3}$ are also observed.

$\mathrm{CoAcr}_{2}$. The sample of $\mathrm{CoAcr}_{2}$ consists of glassy shapeless particles colored from light-orange (in transmitted light) to yellow (in thick layers). The average size of the particles is about $100-150 \mu \mathrm{m}$, although smaller particles (less than $10 \mu \mathrm{m})$ are also present. The particles do not rotate the plane of polarization. The specific surface of the starting sample is equal to $20.0 \mathrm{~m}^{2} / \mathrm{g}$ (Table).

$\mathbf{N i A c r}_{2}$. The powder of $\mathrm{NiAcr}_{2}$ has the extended $S_{\mathrm{sp}}^{0}$ and consists of glassy particles as plates of the various shape and size (Table). Some particles have sizes as high as $1 \mathrm{~mm}$. In thin layers they are of bright green color, transparent and do not rotate the plane of polarization in skew polarizers. It is interesting that for some large particles $(\approx 30$ mass $\%$ ) the scarce nontransparent impregnations are observed in the transmitted light. Their shape is close to spherical one and sizes are about $5-10 \mu \mathrm{m}$. The impregnations consist of more small formations (less than $1 \mu \mathrm{m})$.

$\mathrm{CoMal}_{2}$. The initial powder of $\mathrm{CoMal}_{2}$ consists of transparent particles, which rotate the plane of polarized light in skew polarizers and occur both as crystalline flattened prisms (in some cases, they are well-faceted) with average size $\approx 50 \times 15 \times 5 \mu \mathrm{m}^{3}$ (fraction 1 ) and as shapeless glassy particles with size $5-70 \mu \mathrm{m}$, which exhibit no pronounced optical activity (fraction 2). The characteristic sizes are given in Table. This is associated with the conditions of crystallization in the course of synthesis and characterizes the morphological composition of cobalt maleate. Fraction 1 is a well crystallized compound. Some large crystals have macrodefects as spalls and cracks. The estimated weight ratio of fractions 1 and 2 was $1: 1$.

$\mathbf{F e A c r}_{6}$. Optical microscopic examinations showed that the starting $\mathrm{FeAcr}_{6}$ sample was shapeless glassy aggregates with the average size of $40-60 \mu \mathrm{m}$ consisting of blocks which are smaller by order (Table). Both aggregates and blocks are amorphous, they exhibit no optical activity in transmitted light.

FeMal $_{6}$. The morphology of the FeMal 6 powder is close to those of FeAcr . $_{6}$ They consist of the blocks (Table) of shapeless amorphous glassy aggregates which are straw in thin layers and their sizes are about $80-100 \mu \mathrm{m}$. 
TABLE

Morphology characteristics of the starting metal carboxylates.

\begin{tabular}{|c|c|c|c|c|}
\hline Sample & $\begin{array}{l}\text { The shape of } \\
\text { particle } \\
\text { agglomerates, } \\
\text { the color in } \\
\text { thin layers }\end{array}$ & $\begin{array}{c}\text { The size of blocks } \\
\qquad L_{\mathrm{OM}}\left[\mu \mathrm{m}^{3}\right]^{*}\end{array}$ & $S_{\mathrm{sp}}^{0}\left[\mathrm{~m}^{2} / \mathrm{g}\right]$ & $\bar{L}[\mu \mathrm{m}]^{*}$ \\
\hline $\mathrm{CuAcr} 2$ & $\begin{array}{l}\text { Plate crystals, } \\
\text { bright green }\end{array}$ & $(5 \div 20) \times(5 \div 50) \times(1 \div 5)$ & 14.7 & 140.0 \\
\hline $\mathrm{CoAcr}_{2}$ & $\begin{array}{l}\text { Glassy blocks, } \\
\text { light orange }\end{array}$ & $\approx 100 \div 150$ & 20.0 & 100.0 \\
\hline $\mathrm{NiAcr}_{2}$ & $\begin{array}{l}\text { Plates, light } \\
\text { green }\end{array}$ & $(60 \div 100)^{2} \times(\approx 5)$ & 15.9 & 130.0 \\
\hline $\mathrm{CoMal}_{2}$ & $\begin{array}{l}\text { Plate prismatic } \\
\text { crystals and } \\
\text { glassy blocks, } \\
\text { pink }\end{array}$ & $\begin{array}{c}\approx 50 \times 15 \times 5^{* *} \\
5 \div 70^{* * *}\end{array}$ & 30.0 & 70.0 \\
\hline $\mathrm{FeAcr}_{6}$ & $\begin{array}{l}\text { Glassy blocks, } \\
\text { straw }\end{array}$ & $\approx 1 \div 5$ & 15.0 & 140.0 \\
\hline $\mathrm{FeMal}_{6}$ & $\begin{array}{l}\text { Glassy blocks, } \\
\text { straw }\end{array}$ & $\approx 5 \div 10$ & 21.0 & 90.0 \\
\hline $\mathrm{FeCoAcr}_{8}$ & $\begin{array}{l}\text { Glassy blocks, } \\
\text { light brown }\end{array}$ & $\approx 10 \div 15$ & 8.1 & 255 \\
\hline $\mathrm{Fe}_{2} \mathrm{CoAcr}_{14}$ & $\begin{array}{l}\text { Glassy blocks, } \\
\text { light brown }\end{array}$ & $\approx 10 \div 15$ & 9.0 & 230 \\
\hline $\mathrm{FeNiAcr}_{14}$ & $\begin{array}{l}\text { Plate } \\
\text { agglomerates, } \\
\text { yellow-orange }\end{array}$ & $(5 \div 200)^{2} \times \approx 10$ & 8.5 & 260.0 \\
\hline NiPAcr-1 & $\begin{array}{l}\text { Plate } \\
\text { agglomerates, } \\
\text { straw }\end{array}$ & $(5 \div 120)^{2} \times \approx 10$ & 35.0 & 60.0 \\
\hline NiPAcr-2 & $\begin{array}{l}\text { Blocks } \\
\text { agglomerates, } \\
\text { straw }\end{array}$ & $\approx 15 \div 20$ & 31.6 & 67.0 \\
\hline
\end{tabular}

${ }^{*} L_{\mathrm{OM}}$ is an average size of the particles on the data of the OM; $L_{\mathrm{s}}$ is an average size of the particles on the data of $S_{\mathrm{sp}}^{0}$; ${ }^{* *} \mathrm{CoMal}_{2}$, the plane crystal prism; ${ }^{* * *} \mathrm{CoMal}_{2}$, glassy blocks 
$\mathbf{F e C o A c r}_{8}, \mathbf{F e}_{2} \mathbf{C o A c r}_{14}$. The data of the optical studies testify that the FeCoAcr 8 and $\mathrm{Fe}_{2} \mathrm{CoAcr}_{14}$ samples are morphologically similar. The compounds are light brown transparent crystals with irregular shapes. Their average sizes are given in Table, the size distributions are fairly narrow. The crystals form agglomerates 100 to $150 \mu \mathrm{m}$ in size, some of which reach $\approx 1$ to $2 \mathrm{~mm}$.

$\mathbf{F e}_{2} \mathbf{N i A c r}{ }_{14}$. Cocrystallite is the yellow powder in the reflected light. It consists of shapeless plates which are transparent in the transmitted light, the color of which changes from light-yellow in the thin layers to bright orange in the thick layers. The particles are characterized by the wide distribution of the size (Table), some reach $300-500 \mu \mathrm{m}$.

NiPAcr-1, NiPAcr-2. Though the methods of their synthesis are different the topography of the compounds is characterized by the identical pattern. These are agglomerates of transparent shapeless blocks, their average sizes are given in Table. The agglomerate sizes amount to a hundred microns. In the polarized light the particles are not active.

Thus, the morphologies of the compounds studied are close. Being highly dispersed, the particles are amorphous formations as blocks and agglomerates, with rare exceptions $\left(\mathrm{CuAcr}_{2}, \mathrm{CoMal}_{2}\right)$. It should be mentioned when the samples are prepared dry, most of the compounds $\left(\mathrm{CoAcr}_{2}, \mathrm{NiAcr}_{2}, \mathrm{CoMal}_{2}, \mathrm{NiPAcr}_{2}-1\right.$, $\mathrm{NiPACr}_{2}-2$ ) are opalescent in the polarized light. It does not depend on the degree of rotation and disappears, when the observations are carried out in immersion oil (the blocks become transparent and optically inert). This indicates an appreciable porosity of the material (in the case of $\mathrm{NiPacr}_{2}$ the size of the element of periodicity amounts to $50-100 \mu \mathrm{m}$ ). The comparison of the $L_{\mathrm{OM}}$ and $L_{\mathrm{S}}$ average sizes of the particles (under the assumption that the particles are spherical and the average density $\rho \approx 2.7 \mathrm{~g} / \mathrm{cm}^{3}$ ) shows that $L_{\mathrm{S}} \leq L_{\mathrm{OM}}$ requirement is realized, confirming also the possible porosity of the particles. For subsequent thermal transformations it is important that the majority of large formations include macrodefects, such as cracks and chips.

\section{D. Evolution of the morphology during thermal transformations of metal-containing monomers}

The systematic OM studies of the evolution of morphology of solid phase during thermolysis of the compounds and of the data on their specific surface show that the thermal transformation proceeds homogeneous-heterogeneously [2-8]. At the same time the transformation of the individual compound is characterized by both common and specific features.

$\mathbf{C u A c r} 2\left(T_{\text {therm }}=463-513 \mathrm{~K}\right)$. During thermolysis the parameter $S_{\mathrm{sp}}$ grows three times more than the $S_{\mathrm{sp}}^{0}\left(14.7 \mathrm{~m}^{2} / \mathrm{g}\right)$. The specific surface by the end of transformation $S_{\mathrm{sp}}^{\mathrm{f}}$ depends on $T_{\text {therm }}$ in a peculiar way. With increasing $T_{\text {therm }}$ up to $493 \mathrm{~K}$ the $S_{\mathrm{sp}}^{\mathrm{f}}$ first increases: $48.0(463 \mathrm{~K}), 53.8(473 \mathrm{~K}), 60.8 \mathrm{~m}^{2} / \mathrm{g}(493 \mathrm{~K})$, and then decreases: $59.4(503 \mathrm{~K}), 43.7 \mathrm{~m}^{2} / \mathrm{g}(513 \mathrm{~K})$. This apparently is associated 
with agglomeration of the products. Thermolyzed products are agglomerates of nontransparent dark-brown particles with metallic lustre (apparently due to the formation of metal copper particles). Their sizes are 2 to $100 \mu \mathrm{m}$. Among agglomerates there are small crystals of cubic shape and of the size $(2 \div 5)^{3} \mu \mathrm{m}^{3}$, transparent particles as prism needles up to $20 \mu \mathrm{m}$ of length and $1 \div 5 \mu \mathrm{m}$ in diameter, as well as glassy formations which rotate the plane of polarization in the skew polaroids. The content of transparent particles amounts to $20-30 \mathrm{wt} \%$. But with growing $T_{\text {therm }}$ it decreases and does not exceed $10 \mathrm{wt} \%$ at $613 \mathrm{~K}$. The glassy particles with impregnations like nontransparent islands, which do not rotate the plane of polarization, have been observed. At $613 \mathrm{~K}$ the average sizes of nontransparent particles are still larger.

$\mathrm{CoAcr}_{2}$. Optical microscopy studies have shown that the main part of the decay product consists of opaque particles with a verage size $c a .5 \mu \mathrm{m}$ (up to $40 \%$ ), varying in dimensions from $60 \mu \mathrm{m}$ to less than $1 \mu \mathrm{m}$. The microparticles $(<1 \mu \mathrm{m})$ account for $\approx 40-45$ mass $\%$. All these particles are black. Moreover, they display magnetic properties and can be tentatively identified as Co or its oxides. The transparent glassy particles $(\approx 15-20 \%)$, either isolated or covering the opaque particles and retaining their color in polarized light, were also observed.

$\mathbf{N i A c r}_{2}\left(T_{\text {therm }}=573-633 \mathrm{~K}\right)$. During thermolysis of $\mathrm{NiAcr}_{2}$ dispersity of the solid product increases and changes from $S_{\mathrm{sp}}^{0}=15.9 \mathrm{~m}^{2} / \mathrm{g}$ to $S_{\mathrm{sp}}^{\mathrm{f}} \approx 29.5 \mathrm{~m}^{2} / \mathrm{g}$ at the end of the transformation. The change in $T_{\text {therm }}$ does not influence significantly the dispersity of the products. The yield product is a black ferromagnetic powder consisting of two fractions: particles which are nontransparent in the transmitted light ( $>70 \mathrm{wt} \%$ ), and particles appearing as nontransparent impregnations homogeneously distributed in relative transparent medium. The sizes of these particles are about $10 \mu \mathrm{m}$ and their amount is increased both in volume and on the surface of the particles during conversion. Nontransparent particles are small formations (less than $10 \mu \mathrm{m}$ ) and their aggregations (up to $100 \mu \mathrm{m}$ ), which get separated into blocks of $10-20 \mu \mathrm{m}$ under a weak mechanical force. The small particles can form agglomerate chain structures that, apparently, cause their ferromagnetism.

$\mathbf{C o M a l}_{2}\left(T_{\text {therm }}=613-643 \mathrm{~K}\right)$. The dispersity of the products of $\mathrm{CoMal}_{2}$ transformation is practically not changed during thermolysis. The specific surface of the samples under study remained virtually unchanged upon thermolysis and was $30.0 \pm 2.0 \mathrm{~m}^{2} \mathrm{~g}^{-1}$ (Table). The behavior of fractions 1 and 2 during thermal conversion is different. Optical studies of the changes in the topography of particles of fraction 1 demonstrated that, even at low degrees of gas evolution, particles lost their ability to rotate the plane of polarization of transmitted light. This indicates that the sample became amorphous and is, apparently, associated with high rates of dehydration and polymerization, which occurred before the major gas evolution. In the course of conversion, a dark film was formed on particles, which points to the fact that surface reaction occurred, a dislocation decorated network appeared, 
and the reactions were localized on growth defects. All the aforesaid are evidence for the heterogeneous character of conversion of crystals of the fraction 1.

Reaction centers and a dark film are observed on shapeless blocks (fraction 2), and a dislocation network is absent. At the end of conversion of $\mathrm{CoMal}_{2}$, a powder of the product consists of nontransparent particles, which retain the shape of the initial particles.

$\mathbf{F e A c r}_{6}\left(T_{\text {therm }}=473-643 \mathrm{~K}\right)$ and $\mathbf{F e M a l}_{6}\left(T_{\text {therm }}=573-643 \mathrm{~K}\right)$. The character of evolution of morphology for the samples of FeAcr 6 and FeMal $_{6}$ is the same. The specific surface practically does not change during thermolysis and is close to $S_{\mathrm{sp}}^{0}$ (Table). The conversion results in the enlargement of agglomerates (up to $1 \mathrm{~mm}$ ); consequently, the contribution of large agglomerates increases. Taking into account that in this case $S_{\mathrm{sp}}$ is practically not changed one can suppose that the porosity of these formations is high enough. Under weak mechanical disturbance large agglomerates split into small blocks of shapeless particles of $1-3 \mu \mathrm{m}$ in size. At low $T_{\text {therm }}$ and low degree of conversion the particles retain the transmittance, exhibit no activity in polarized light, contain no defects, and are homogeneously colored. At early stage of conversion the products are non-magnetic. With the increase in $T_{\text {therm }}$ and conversion the particles become dark brown. The number of agglomerates decreases, the isolated glassy plates of large sizes $(60-100 \mu \mathrm{m}$ for $\mathrm{FeAcr}_{6}$ and $50-150 \mu \mathrm{m}$ for $\mathrm{FeMal}_{6}$ ) do appear. They easily split into blocks. During thermolysis the plates become dark, but they remain relatively transparent as thin layers. At $T_{\text {therm }}>583 \mathrm{~K}$ the products of transformations of $\mathrm{FeAcr}_{6}$ and $\mathrm{FeMal}_{6}$ are magnetic. It should be mentioned that OM studies reveal large defects of the surface of the large particles, such as numerous craters of $0.5-2.0 \mu \mathrm{m}$.

$\mathbf{F e C o A c r}_{8}\left(T_{\text {therm }}=613-663 \mathrm{~K}\right), \mathbf{F e}_{2} \mathbf{C o A c r}_{14}\left(T_{\text {therm }}=613-663 \mathrm{~K}\right)$, $\mathbf{F e}_{2} \mathbf{N i A} \mathbf{c r}_{14}\left(T_{\text {therm }}=603-643 \mathrm{~K}\right)$. Morphological changes in these compounds are characterized by some general features. During thermal transformation of cocrystallites an increase in the dispersity of solid phase products is observed. At the end of gas evolution the values of $S_{\mathrm{sp}}^{\mathrm{f}}$ reach $13.6\left(\mathrm{FeCoAcr}_{8}\right), 11.3\left(\mathrm{Fe}_{2} \mathrm{CoAcr}_{14}\right)$, $14.8 \mathrm{~m}^{2} / \mathrm{g}\left(\mathrm{Fe}_{2} \mathrm{NiAcr}_{14}\right)$, so they are higher than those for $S_{\mathrm{sp}}^{0}$ (Table). According to OM observations during thermolysis the enlargement of aggregations proceeds. They are brittle porous formations consisting of glassy plates (about $100-120 \mu \mathrm{m}$ ). As above mentioned, the transparency of these plates evenly declines: with the development of gas evolution, the color changes from light to deep brown. This indicates that thermolysis of cocrystallites proceeds homogeneously in the bulk. At the end of transformation the particles lost their transparency. The size of agglomerates decreases, resulting in the formation of shapeless blocks, which split into grits of small shapeless particles under the mechanical disturbance (Fig. 1). The sizes of these particles are $\approx 1.0-2.0 \mu \mathrm{m}$ (FeCoAcr, $\mathrm{Fe}_{2} \mathrm{CoAcr}_{14}$ ), and $10.0-15.0 \mu \mathrm{m}\left(\mathrm{Fe}_{2} \mathrm{NiAcr}_{14}\right)$. In the reflected light the particles are black. The yield products of the transformation of cocrystallites are ferromagnetic. The small nontransparent particles resulting at the end of thermal transformation of $\mathrm{Fe}_{2} \mathrm{NiAcr}_{14}$ 


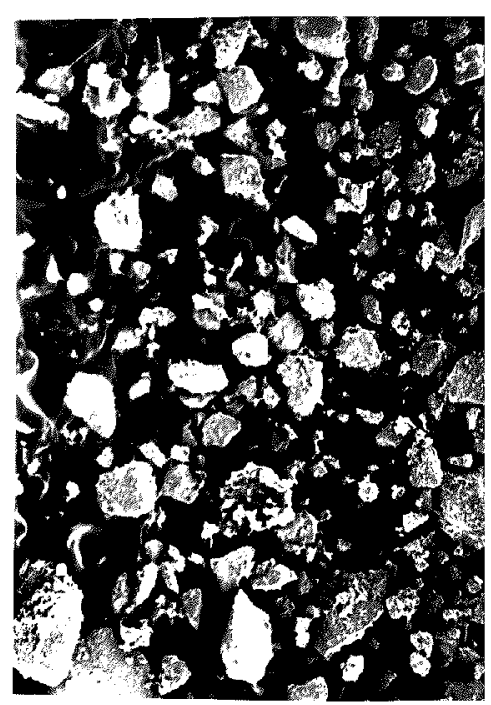

Fig. 1. OM photograph of the products of thermolysis of $\mathrm{NiAcr}_{2}$ at $613 \mathrm{~K}, \times 100$.

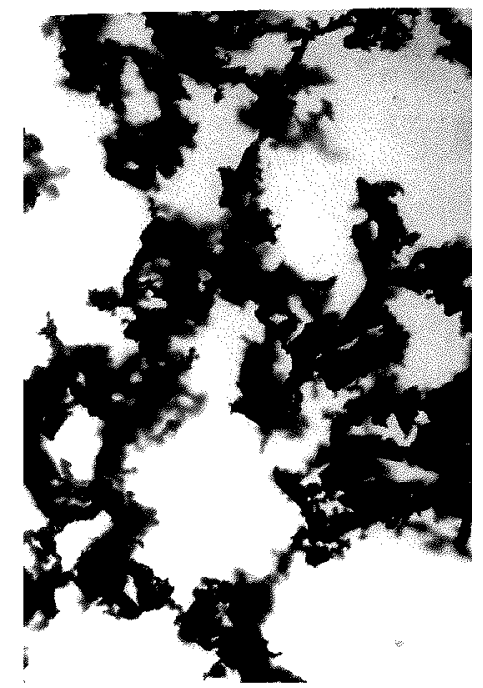

Fig. 2. OM photograph of agglomerate chains in the product of thermolysis of $\mathrm{Fe}_{2} \mathrm{NiAcr}_{14}$ at $643, \times 500$.

$(\leq 10.0-15.0 \mu \mathrm{m})$ form fractal-like agglomerates, such as small chains (Fig. 2, 3), like those for $\mathrm{NiAcr}_{2}$. Ferromagnetism of the particles is apparently determined by such a structure. The average length of the chain aggregates consisting of $6-7$ 


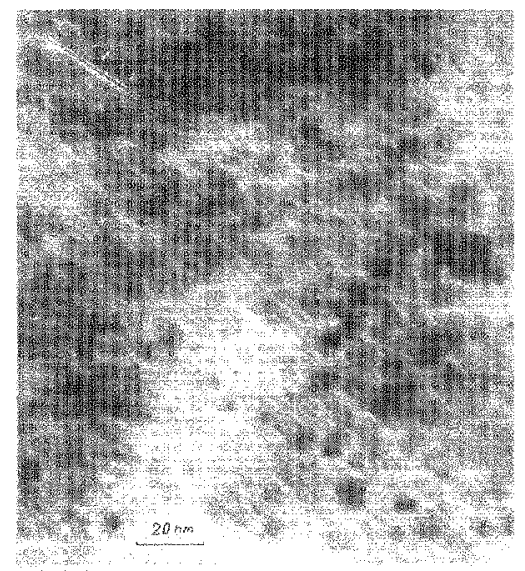

Fig. 3. Electron microscope photograph of the product of thermolysis of $\mathrm{Fe}_{2} \mathrm{CoAcr}$ at $663 \mathrm{~K}, \times 300,000$.

small particles may reach $50-70 \mu \mathrm{m}$.

NiPAcr-1 $\left(T_{\text {therm }}=563-598 \mathrm{~K}\right), \mathbf{N i P A c r - 2}\left(T_{\text {therm }}=573-643 \mathrm{~K}\right)$. During thermolysis the specific surface is not changed. At the end of thermolysis the $S_{\mathrm{sp}}^{\mathrm{f}}$ values are equal to $31.0( \pm 3.0) \mathrm{m}^{2} / \mathrm{g}$ and are close to those of $S_{\mathrm{sp}}^{0}$ (Table). The products of the transformation are black powders in the reflected light. The particles are agglomerates of the size up to a hundred microns, consisting of blocks of $15-20 \mu \mathrm{m}$. Agglomerates are easily separated under a mechanical disturbance. The sample studied consisted of two fractions: black nontransparent magnetic particles and semitransparent non-magnetic formations, the mass ratio being $\approx 2: 3$ (NiPAcr-1) and $\approx 3: 7$ (NiPAcr-2). OM observations in polarized light show that the particles exhibit opalescence independent of the degree of rotation, that may be associated with high porosity of the material. After putting the sample into immersion medium the opalescence is lost - the particles become inactive.

Thus, the analysis of the character of morphology changes ${ }^{\dagger}$ indicates that in spite of individual behavior of each compound, one can see some universal features. For crystal hydrates at early stages of conversion the thermolysis leads to partial loss of transparence of the particles. Their surface becomes rough due to dehydration reaction. At $\beta \geq 0.15$ the dispersion of large blocks is observed. Thus, for the samples of $\mathrm{NiAcr}_{2}$ at $\beta \approx 0.15 \mathrm{~L}_{\mathrm{OM}}$ is equal to $\approx 30-40 \mu \mathrm{m}$, $\beta \approx 0.22 L_{\mathrm{OM}}-\approx 20-30 \mu \mathrm{m}, \beta \approx 0.29 L_{\mathrm{OM}}-\approx 10-20 \mu \mathrm{m}$. Also the small particles are observed $(<1 \mu \mathrm{m})$. Their content increases with growing $\beta$ and at $\beta \geq 0.29$ it is higher than that of large particles. During thermolysis at $\beta>$ $0.2-0.30$ the transparent particles become dark and local loss of transparency is observed in the region of macrodefects. This shows a reaction heterogeneity within

${ }^{\dagger}$ The degree of conversion is estimated on the mass loss of the sample $\beta=\Delta m / m_{0}$, where $m_{0}$ is the initial weight of the sample. 
the particle. Such a topography structure shows the homogeneous-heterogeneous character of the transformation. The reactivities of the particles of the compounds are different. Thus, a part of the particles (for example, in case of $\mathrm{FeAcr}_{6}$, $\mathrm{FeMal}_{6}, \mathrm{NiAcr}_{2}, \mathrm{Fe}_{2} \mathrm{NiAcr}_{14}$ ) even at $\beta \approx 0.30-0.40$ becomes nontransparent, while at the same time there are transparent ones among small particles (about $30.0 \mathrm{wt} \%$ in case of $\mathrm{NiAcr}_{2}$ ). At $\beta>0.40-0.50$ all particles are nontransparent.

\subsection{Electron-microscopic studies}

Detailed electronic microscopic observations of topography and microdiffraction of the products of thermolysis of $\mathrm{FeAcr}_{6}, \mathrm{FeCoAcr}_{8}, \mathrm{Fe}_{2} \mathrm{CoAcr}_{14}, \mathrm{Fe}_{2} \mathrm{NiAcr}_{14}$ and $\mathrm{CoMal}_{2}$ have shown that they have the similar morphology. It is characterized by practically spherical particles of electron density having narrow size

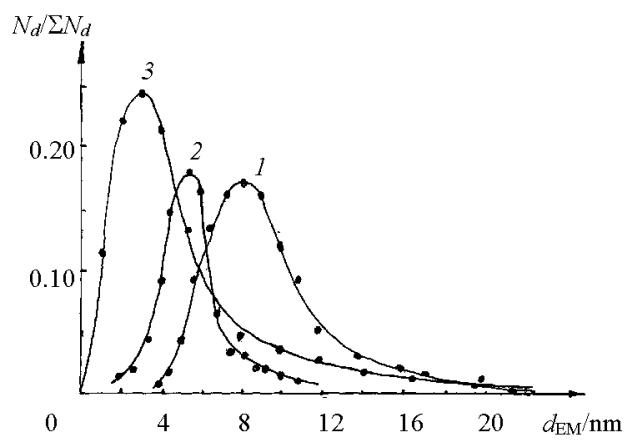

Fig. 4. The size distribution of the particles (from the electron microscopy data): 1 $\mathrm{FeAcr}_{3}\left(\sum N_{d}=3315\right), 2-\mathrm{Fe}_{2} \mathrm{CoAcr}_{14}\left(\sum N_{d}=2319\right), 3-\mathrm{CoMal}_{2}\left(\sum N_{d}=390\right)$; $N_{d}$ is the number of particles with the size $d$.

distribution and allotted in low-electron-density matrix (Fig. 4). The particles are uniformly distributed in the matrix at an average distance of about $8.0 \mathrm{~nm}$. The average particle sizes, $\bar{d}_{\mathrm{EM}}$, are $6.0-13.0 \mathrm{~nm}$ in the case of $\mathrm{FeAcr}_{6}$ (based on the data of electron diffraction, the main product is $\left.\mathrm{Fe}_{3} \mathrm{O}_{4}\right), 6.0 \mathrm{~nm}$ for $\mathrm{FeCoAcr}_{8}$ and $\mathrm{Fe}_{2} \mathrm{CoAcr}_{14}\left(\mathrm{Fe}_{3} \mathrm{O}_{4}, \mathrm{CoO}, \mathrm{Fe}_{2} \mathrm{CoO}_{4}\right)$, and $6 \mathrm{~nm}$ for $\mathrm{CoMal}_{2}$ (mainly $\mathrm{CoO}$ ). The particles are present both individually and as agglomerates (about 50 mass \%) of three to 10 particles.

Thus, in the course of thermal transformation of compounds studied the material consists of nanosized metal particles with narrow size distribution stabilized by polymer matrix.

\section{References}

[1] A.D. Pomogailo, A.S. Rozenberg, I.E. Uflyand, Metal Nanoparticles in Polymers, Khimiya, Moscow 2000.

[2] E.I. Alexandrova, G. I. Dzhardimalieva, A.S. Rozenberg, A.D. Pomogailo, Russ. Chem. Bull. 42, 254 (1993) (in English). 
[3] E.I. Alexandrova, G.I. Dzhardimalieva, A.S. Rozenberg, A.D. Pomogailo, Russ. Chem. Bull. 42, 259 (1993) (in English).

[4] A.S. Rozenberg, G.I. Dzhardimalieva, A.D. Pomogailo, Polym. Adv. Technol. 9, 527 (1998).

[5] A.S. Rozenberg, E.I. Alexandrova, N.P. Ivleva, G.I. Dzhardimalieva, A.V. Raevskii, O.I. Kolesova, I.E. Uflyand, A.D. Pomogailo, Russ. Chem. Bull. 47, 259 (1998) (in English).

[6] A.S. Rozenberg, E.I. Alexandrova, G.I. Dzhardimalieva, A.N. Titkov, A.D. Pomogailo, Russ. Chem. Bull. 42, 1666 (1993) (in English).

[7] A.T. Shuvaev, A.S. Rozenberg, G.I. Dzhardimalieva, N.P. Ivleva, V.G. Vlasenko, T.I. Nedoseikina, T.A. Lyubeznova, I.E. Uflyand, A.D. Pomogailo, Russ. Chem. Bull. 47, 1460 (1998) (in English).

[8] A.S. Rozenberg, E.I. Alexandrova, G.I. Dzhardimalieva, N.V. Kir'ykov, P.E. Chizhov, V.I. Petinov, A.D. Pomogailo, Russ. Chem. Bull. 44, 858 (1995) (in English). 